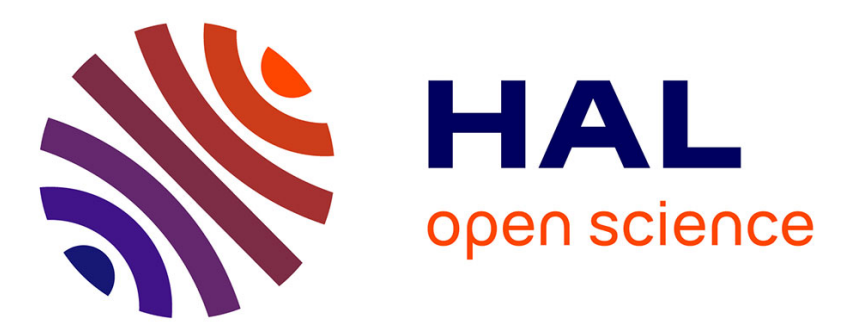

\title{
Matrix Degradation during High Speed Extrusion of Polypropylene/Clay Nanocomposites - Influence on Filler Dispersion
}

Guillaume Normand, Edith Peuvrel-Disdier, Bruno Vergnes

\section{To cite this version:}

Guillaume Normand, Edith Peuvrel-Disdier, Bruno Vergnes. Matrix Degradation during High Speed Extrusion of Polypropylene/Clay Nanocomposites - Influence on Filler Dispersion. International Polymer Processing, 2016, 31 (4), pp.508-516. 10.3139/217.3285 . hal-01368846

HAL Id: hal-01368846

https://hal-mines-paristech.archives-ouvertes.fr/hal-01368846

Submitted on 13 Apr 2017

HAL is a multi-disciplinary open access archive for the deposit and dissemination of scientific research documents, whether they are published or not. The documents may come from teaching and research institutions in France or abroad, or from public or private research centers.
L'archive ouverte pluridisciplinaire HAL, est destinée au dépôt et à la diffusion de documents scientifiques de niveau recherche, publiés ou non, émanant des établissements d'enseignement et de recherche français ou étrangers, des laboratoires publics ou privés. 


\title{
Matrix degradation during high speed extrusion of polypropylene/clay nanocomposites - influence on filler dispersion
}

\author{
G. Normand, E. Peuvrel-Disdier, B. Vergnes*
}

MINES ParisTech, PSL Research University, CEMEF - Centre de Mise en Forme des Matériaux, UMR CNRS 7635, CS 10207, 06904 Sophia-Antipolis, France

*Corresponding author: $\quad$ B. Vergnes

bruno.vergnes@mines-paristech.fr 


\begin{abstract}
We prepared polypropylene/organoclay nanocomposites by melt blending in a twin-screw extruder, exploring the domain of high screw speeds (up to $1100 \mathrm{rpm}$ ). The samples were characterized at both microscale (size of agglomerates) and nanoscale (level of exfoliation). We show that, despite a satisfactory exfoliation, the polymer matrix suffered important thermomechanical degradation by chain scission. We propose a way to correct this degradation on the viscosity curves and we confirm that high screw speeds are not necessarily favorable to clay exfoliation, essentially because of the too high melt temperatures encountered during the process.
\end{abstract}

Keywords: Twin screw extrusion, Nanocomposite, High speed, Degradation, Dispersion 


\section{Introduction}

Polymer/clay nanocomposites were first developed in the Toyota Research Laboratories by Usuki et al. (1992). Since this pioneering work, it has been shown that mixing a small amount of clay ( $<5 \mathrm{wt} \%$ ) with a polymer matrix could improve many properties such as mechanical (Cho and Paul, 2001; Gloaguen and Lefebvre, 2001; Hong et al., 2005; Hedge et al., 2013), barrier (Messersmith and Giannelis, 1995; Yano et al., 1997) and flame retardancy properties Doh and Cho, 1998; Gilman et al., 2000).

The interest of organoclay compared to other nanofillers is their important specific area. Indeed, clay presents itself as aggregates, composed of tactoids which are made of several tenths of individual layers stacked together. The difficulty during processing consists in separating those different layers in order to reach the full reinforcing potential of the organoclay. However, the clay is naturally hydrophilic and thus difficult to disperse in a nonpolar matrix. Therefore, the clay usually undergoes a chemical treatment, allowing to increase the interlamellar distance, and to make it organophilic.

This chemical modification is often enough to allow a good dispersion in polar matrices such as polyurethane (Wang and Pinnavaia, 1998) and epoxy (Massam and Pinnavaia, 1998). However, in non-polar matrices, a compatibilizer must be used to increase the chemical affinity between clay and matrix. For polypropylene (PP), the most common compatibilizer is polypropylene grafted with maleic anhydride (PP-g-MA), which has proven to allow a good dispersion of the clay with an exfoliated structure (Kawasumi et al., 1997; Lertwimolnun and Vergnes, 2005).

PP/organoclay nanocomposites appear as interesting materials because PP is affordable, presents good mechanical properties and an easy processability. In order to prepare such nanocomposites, the most interesting option is melt blending, using a twin-screw extruder. This method presents several advantages, as it is a continuous process, with high levels of 
mechanical energy, and flexibility: screw profile and processing conditions (screw speed, feed rate, barrel temperature) can be easily modified to optimize the clay dispersion state.

In order to characterize the dispersion state, microscopic observations and X-ray diffraction are commonly used on polymer/clay nanocomposites. Scanning electron microscopy allows the observation of the clay aggregates at microscale. X-ray diffraction helps to characterize the interlayer distance, and thus the intercalation state. Melt rheology in small amplitude oscillatory shear is also often used to characterize such materials, because it is very sensitive to the clay exfoliation level, and hence gives a good idea of the dispersion achieved at nanoscale during melt processing.

The influence of processing conditions such as screw speed (Incarnato et al., 2003; Lertwimolnun and Vergnes, 2006; Modesti et al., 2006; Lin et al., 2009; Domenech et al., 2012), feed rate (Fasulo et al., 2004; Scatteia et al., 2006; Lertwimolnun and Vergnes, 2007) and barrel temperature (Modesti et al., 2005; Shah and Paul, 2006; Domenech et al., 2012) on the clay dispersion state has been widely studied in the literature. It has been shown that a low feed rate is beneficial for the dispersion, because a long residence time helps to achieve a good level of exfoliation (Domenech et al., 2012). However, feed rate seems to have a limited impact on intercalation (Lertwimolnun and Vergnes, 2006). It is also generally admitted that a low temperature is better for dispersion because it increases the level of shear stresses during melt processing (Modesti et al., 2005; Domenech et al., 2012). It also prevents the degradation of the components, as both polypropylene, PP-g-MA and organoclay can be degraded if the temperatures reached during melt processing are too high (Barbas et al., 2013). In some cases, the degradation of the clay chemical modifier can cause polymer chain scission, as with polystyrene (Nassar et al., 2005), polyethylene (Shah and Paul, 2006) and polyamide (Fornes et al., 2003) matrices, but it has not been reported yet with polypropylene. 
It has also been shown that increasing screw speed helps to achieve a good level of exfoliation, because increasing shear stress helps the separation of the individual layers (Cho and Paul, 2001; Lertwimolnun and Vergnes, 2006). However, Peltola et al. (2006) obtained good exfoliation levels regardless of the screw speed used, reporting limited impact of this parameter. Only a few studies have shown the impact of very high screw speeds (up to 1200 rpm). Fel et al. (2014) reported these effects on the residence time distribution. Louizi et al. (2014) noticed an improvement of the morphology and properties of nanocomposites made of PP/EPR and silica around 800 rpm, and a degradation of the matrix above. The main purpose of this paper is thus to explore the potentiality of modern extruders, and specifically of high screw speeds, for the preparation of PP/organoclay nanocomposites.

\section{Materials and Methods}

\subsection{Materials}

The polypropylene used (Moplen HP400R, LyondellBasell) is an injection grade isotactic homopolymer, with a MFI of $25(2.16 \mathrm{~kg} / 10 \mathrm{~min})$ and a melting temperature of $164^{\circ} \mathrm{C}$. The PP-g-MA (Epolene G-3015, Eastman) has a MFI of 40 (2.16 kg/10min) and a melting temperature of $162^{\circ} \mathrm{C}$. The organoclay (OMMT) is a Cloisite 20 (C20), provided by BYK Additives (formerly Southern Clay Products). It is a Na+-montmorillonite chemically modified by dimethyl di(hydrogenated tallowalkyl) quaternary ammonium. It has a density of 1.77 g.cm ${ }^{-3}$, and a cation exchange capacity of $95 \mathrm{meq} / 100 \mathrm{~g}$.

\subsection{Samples preparation}

Before compounding, OMMT and PP-g-MA were dried for 15 hours at $80^{\circ} \mathrm{C}$ under vacuum. The PP/PP-g-MA/C20 composites were prepared with respective weight fractions of 85/10/5, using a laboratory scale co-rotating twin-screw extruder (ThermoFisher Rheomex PTW24). It had a diameter of $24 \mathrm{~mm}$ and a $L / D$ ratio of 40 . The extruder was fed with two gravimetric 
feeders: the first one (Brabender DDW-MD3-DDSR20-10) allowed to introduce the polymer pellets (PP + PP-g-MA) in barrel 1, and a second one (Brabender DDW-MD1-MT-1) allowed the introduction of the clay in barrel 3 (Fig. 1). The barrel temperature was set à $180^{\circ} \mathrm{C}$. Five screw speeds were chosen: 100, 300, 600, 900 and $1100 \mathrm{rpm}$. The feed rates were set at 2.47 $\mathrm{kg} / \mathrm{h}$ for the matrix (PP + PP-g-MA) and $0.13 \mathrm{~kg} / \mathrm{h}$ for the clay, hence a total feed rate of 2.6 $\mathrm{kg} / \mathrm{h}$. The clay amount was systematically checked for each sample by weighing solid residuals after complete matrix calcination in an oven at $600^{\circ} \mathrm{C}$. Extrudate temperatures were measured at the die exit for each extrusion condition using a manual thermocouple.

The extrudate was cooled down in water at die exit before being granulated. For the various characterizations, the nanocomposite pellets were melted and compressed in a hydraulic press (Carver M 3853-0) at a pressure of $20 \mathrm{MPa}$, during 8 minutes at $200^{\circ} \mathrm{C}$. The samples were then disk-shaped, with a $25 \mathrm{~mm}$ diameter and a $1.5 \mathrm{~mm}$ thickness.

\subsection{Microstructure characterization}

In order to characterize the microstructure, the polished surface of the compressed samples was observed by scanning electron microscopy (SEM) with a Philips XL30 ESEM, under an acceleration voltage of $15 \mathrm{kV}$. The size and repartition of the clay agglomerates were characterized using an image analysis software (Visilog 6). It enables the calculation of the clay area ratio $A_{r}$ (expressed in \%):

$$
A_{r}=\frac{A_{\text {clay }}}{A_{\text {total }}} \times 100
$$

where $A_{\text {clay }}$ is the area of the clay agglomerates and $A_{\text {total }}$ the total area analyzed. This parameter characterizes the clay dispersion state at the microscale. Due to the microscope resolution, agglomerates with an equivalent diameter under $5 \mu \mathrm{m}$ were not considered. The total area analyzed was $25 \mathrm{~mm}^{2}$. 
The samples were also observed via transmission electron microscopy (TEM), performed on the CCMA EM Core Facility (University of Nice Sophia Antipolis, France). We used a Jeol JEM 1400, equipped with an Olympus MORADA SIS camera. Before observation, the disk shaped samples were cryofractured. Then, ultra-thin samples were prepared via a cryoultramicrotome (Leica FC6) at a temperature of $-100^{\circ} \mathrm{C}$. Local observations were then performed on the samples under an acceleration voltage of $100 \mathrm{kV}$.

The intercalation state was characterized via X-ray diffraction measurements. The diffractometer used was a PANalytical X'pert Pro MRD, with the $\mathrm{Cu} \mathrm{K} \alpha$ radiation and a wavelength of $\lambda=1,540456 \AA$. A $2 \theta$ range between 1.5 and $10^{\circ}$ was analyzed. The interlamellar distance $d_{001}$ of the clay was calculated using the Bragg's law:

$$
n \lambda=2 d_{001} \sin \theta
$$

where $n$ is the order of the reflexion and $\lambda$ the radiation wavelength.

Small amplitude oscillatory shear rheology measurements were performed using a stresscontrolled Anton Paar MCR-302 rheometer. Frequency sweep measurements were carried out in the molten state at a temperature of $180^{\circ} \mathrm{C}$, a strain of $1 \%$ (i.e. in the linear regime) and a gap of $1.25 \mathrm{~mm}$ under a nitrogen atmosphere. Before the measurements, the samples were stabilized at $180^{\circ} \mathrm{C}$ for 30 minutes. A Carreau-Yasuda model with yield stress was used to describe the complex viscosity $\eta^{*}(\omega)$ dependence with the angular frequency $\omega$ (Lertwimolnun and Vergnes, 2006; Vergnes, 2011):

$$
\eta(\omega)=\frac{\sigma_{0}}{\omega}+\eta_{0}\left[1+(\lambda \omega)^{a}\right]^{\frac{n-1}{a}}
$$

where $\sigma_{0}$ is the apparent melt yield stress, $\eta_{0}$ is the zero-shear viscosity, $\lambda$ is a characteristic relaxation time, $a$ is the Yasuda parameter and $n$ is the shear-thinning index. 
The yield stress $\sigma_{0}$ characterizes the elasticity of the network formed by the clay lamellae. It was shown that, at fixed clay loading, this parameter can be correlated to the exfoliation of the clay, and thus to the efficiency of the dispersion at nanoscale.

\section{Results and Discussion}

\subsection{Microscopic observations}

To characterize the clay dispersion state at microscale, the samples were observed via scanning electron microscopy (SEM). Fig. 2 shows the pictures obtained for the samples prepared at different screw speeds. As the screw speed increases, the number and size of clay agglomerates decreases. This means that the clay aggregates are sheared more severely when the screw speed increases, which explains the decreasing size. The number of clay aggregates decreases when the screw speed increases from 100 to $600 \mathrm{rpm}$, and afterwards the effect of screw speed is not so pronounced, as the visual aspect seems to remain the same.

Fig. 3 shows a quantitative analysis of the SEM pictures, with the evolution of the area ratio with screw speed. At the lowest screw speed $(N=100 \mathrm{rpm})$, the area ratio is rather high (0.6\%), and decreases to a value below $0.1 \%$ at $N=600 \mathrm{rpm}$. Then, as the screw speed increases again, the area ratio shows a slight increase. It therefore appears that, at this scale, the optimal screw speed is around $600 \mathrm{rpm}$, and that higher screw speeds do not improve the state of microscopic dispersion.

TEM observations were also performed on the samples, and the pictures are presented in Fig. 4. At each screw speed, the clay lamellae have been exfoliated, at least partially, and we can observe single clay layers as well as aggregated ones. A few "large" tactoids could be observed for the screw speeds from 100 to $600 \mathrm{rpm}$, with a length between $500 \mathrm{~nm}$ and $1 \mu \mathrm{m}$. It also appears that the number of layers per tactoids decreases between 100 and $900 \mathrm{rpm}$. At higher screw speeds, these tactoids seem smaller, and only a few could be observed, which suggests a better dispersion at nanoscale. 


\subsection{Intercalation state}

The samples were characterized by X-ray diffraction. Fig. 5 shows the diffractograms of the five nanocomposites and pure clay for comparison. For each screw speed, the diffraction peak corresponding to the [001] plane of the clay is shifted to the smaller angles. This indicates that the interlamellar distance was increased during extrusion, through intercalation of the clay galleries by polymer chains. The corresponding interlamellar distances are presented on Fig. 6. The temperatures of the melt at the die exit, measured during extrusion, are also indicated on the graph. For each screw speed, the calculated distance is comprised between 3.6 and 3.9 $\mathrm{nm}$, which indicates an intercalation compared to pure clay $\left(d_{001}=3.28 \mathrm{~nm}\right)$. However, the interlamellar distance decreases as the screw speed increases, which can indicate a degradation of the intercalation state at high screw speed.

A decrease of interlamellar distance with screw speed has been already observed by Domenech et al. (2012), who obtained basal distances inferior to the one of pure clay for nanocomposites prepared at the highest screw speeds (between 500 and $900 \mathrm{rpm}$ ). They attributed this decline to the thermal degradation of the surfactant, due to the high temperatures caused by viscous dissipation. Similar results were reported by Dintcheva and La Mantia (2007) on polyethylene/OMMT nanocomposites. Lertwimolnun and Vergnes (2006) observed no effects of the screw speed on intercalation, but the screw speeds were rather low, comprised between 100 and 300 rpm. Barbas et al. (2014) observed a slight increase of the interlamellar distance when the screw speed increased from 50 to $100 \mathrm{rpm}$, and no evolution at higher screw speeds. The assumption of thermal degradation of the surfactant at high screw speeds is realistic in our case, as the temperatures reached at 900 and $1100 \mathrm{rpm}$ were close to $230^{\circ} \mathrm{C}$, as indicated in Fig. 6. It has been reported in the literature that a significant part of the organomodifier is lost between 190 and $240^{\circ} \mathrm{C}$ (Shah and Paul, 2006; Cervantes-Uc et al., 2007; Cui et al., 2008). 


\subsection{Rheological measurements}

Frequency sweep measurements have been performed on the nanocomposites and the matrix in the molten state (Fig. 7). The evolution of the complex viscosity shows the presence of an apparent yield stress at low frequency for the five nanocomposites at the contrary of the matrix. This indicates the presence of a percolated network formed by the clay platelets (Cassagnau, 2008; Domenech et al., 2014). It confirms a good level of exfoliation whatever the screw speed used.

If the low frequency measurements are sensitive to clay exfoliation, the high frequency ones rather characterize the matrix behavior. However, the curves are crossing at high frequency, the viscosity increasing up to $300 \mathrm{rpm}$ and decreasing above. For the sample extruded at $1100 \mathrm{rpm}$, the viscosity is quite similar to the one of the matrix. To clearly interpret these results, we repeated the extrusion tests with the matrix alone, under the same conditions as for the nanocomposites: five screw speeds $N$ (from 100 to $1100 \mathrm{rpm}$ ), at a flow rate $Q$ of $2.47 \mathrm{~kg} / \mathrm{h}$ and a barrel temperature of $180^{\circ} \mathrm{C}$. We then performed rheological characterization of the samples obtained, in the same conditions as for the nanocomposites.

Fig. 8 shows the evolution of the complex viscosity of the matrix with angular frequency for the different screw speeds. It is clear on this graph that the viscosity of the matrix decreases as the rotational speed increases, reflecting a thermomechanical degradation of the polymer. Indeed, it is well known that, under severe thermal and mechanical conditions, PP suffers chain scissions, reducing both molecular weight and viscosity (Hinsken at al., 1991; Gonzalez-Gonzalez et al., 1998; Canevarolo, 2000). This explains the cross-over of the viscosity curves at high frequency.

It would be interesting to correct the complex viscosity curves of the nanocomposites in order to better analyze the data and correctly assess the rheological behavior. In the same way that one can perform a time/temperature superposition, we propose to use a shift factor $a_{d}$ to 
obtain a master curve by plotting $\eta^{*}(\omega) / a_{d}$ as a function of $\omega a_{d}$. Fig. 9 shows the mastercurve obtained, considering the curve at $100 \mathrm{rpm}$ as a reference $\left(a_{d}=1\right)$. It appears that the curves are very well superimposed, validating the suggested approach. Fig. 10 shows the change in shift factor with the screw speed. At the highest screw speed, it drops to a value of 0.5 , meaning that the viscosity was divided by two in these processing conditions. If we consider only the PP and if we assume that the Newtonian viscosity changes with the molecular weight with a power 3.6 (Leonardi, 1999), we can estimate the order of magnitude of the molecular weight of the degraded products. Starting from $123 \mathrm{~kg} / \mathrm{mol}$ for the virgin PP, we reach 103 $\mathrm{kg} / \mathrm{mol}$ at $1100 \mathrm{rpm}$. These values are in agreement with the order of magnitude of molecular weight evolutions measured by size exclusion chromatography for thermomechanically degraded PP (Gonzalez-Gonzalez et al., 1998; Canevarolo, 2000).

If we assume that the degradation of the matrix is not modified by the presence of the clay, we can now apply these shift factors to the viscosity curves of the nanocomposites to correct the degradation of the matrix. In fact, we can also apply directly a time/degradation superposition to the viscosity curves of the nanocomposites, by assuming that the values at high frequency are perfectly superimposed. We then obtain values of the shift factors very close to the previous ones, what justifies the assumption that the degradation of the matrix is not strongly modified by the presence of the clay. Fig. 11 shows the "corrected" curves. They are now ranked as expected. It appears that the curve corresponding to a screw speed of 300 rpm shows the highest increase of viscosity at low frequency. Curves corresponding to screw speeds of 600, 900 and $1100 \mathrm{rpm}$ are almost superimposed, slightly below the one at $300 \mathrm{rpm}$.

\subsection{Discussion}

The Carreau-Yasuda model with a yield stress was applied to the corrected complex viscosity curves. The yield stress increases rapidly from 240 to 510 Pa when the screw speed increases from $100 \mathrm{rpm}$ to $300 \mathrm{rpm}$ (Fig. 12). Above that speed, the yield stress stabilizes at a slightly 
lower value, around $400 \mathrm{~Pa}$. This implies that beyond $300 \mathrm{rpm}$, the clay exfoliation is not improved. A decrease of the exfoliation at high screw speed was also observed by Barbas et al. (2014) on similar nanocomposites. The authors attributed it to the decreasing matrix viscosity, which may have the effect of reducing the shear stresses and prevent optimal exfoliation. This hypothesis is plausible in our case, as a large decrease in matrix viscosity was observed at high screw speed, due to thermomechanical degradation. The decrease of clay intercalation at high screw speed (Fig. 6) could also limit the exfoliation and explain this evolution.

The area ratio and the melt yield stress allow to characterize the clay dispersion state at both microscale and nanoscale. Several authors (Lertwimolnun and Vergnes, 2007; Médéric et al., 2009; Domenech et al., 2012, 2013) have proposed to correlate the efficiency of the dispersion at these two scales with the specific mechanical energy (SME). To do that, we have first to evaluate the energy provided to the nanocomposite after clay introduction. Experimentally, we can only measure the global SME provided by the extruder and we cannot extract the part devoted to the nanocomposite after the clay introduction. For this reason, we can only calculate the SME provided to the nanocomposite by numerical modelling. We used for that the Ludovic $^{\odot}$ software, dedicated to the calculation of flow parameters in a twinscrew extruder and already largely used for understanding the compounding of nanocomposites (Lertwimolnun and Vergnes, 2006, 2007; Bahloul et al., 2011; Domenech et al., 2012, 2013). Ludovic ${ }^{\circledR}$ is a $1 \mathrm{D}$ modelling software for twin screw extruders, which makes it possible to calculate the main flow parameters (temperature, pressure, shear rate, viscosity, residence time, specific energy, filling ratio, etc.) along the screws. A local one-dimensional approach is adopted. The screws are divided into sub-elements, each element corresponding to the volume occupied by the material around one screw. Computation of the various parameters is done separately for each type of screw element (partially or totally filled right- 
handed screw elements, left-handed screw elements and blocks of staggered kneading disks) and for the die components. The data for the simulation can be split into three main parts: first, a description of the extrusion configuration, such as screw and barrel profiles and die geometry, is necessary. Second, the rheological and thermal properties of the polymer have to be defined. Third, processing conditions must be indicated (feed rate, screw speed, barrel temperatures, heat transfer coefficients).

Fig. 13 shows the evolution of the area ratio and the melt yield stress with the calculated SME. It appears that there is an energy threshold, between 400 and $600 \mathrm{kWh} / \mathrm{t}$, above which both the exfoliation and the dispersion of clay aggregates is not improved. Domenech et al. (2012) also observed, for similar nanocomposites, an energy threshold around $600 \mathrm{kWh} / \mathrm{t}$, beyond which the melt yield stress and the area ratio did not change. Mederic et al. (2009) detected a critical threshold of $140 \mathrm{kWh} / \mathrm{t}$, but for PA12/clay samples prepared in an internal mixer. It seems therefore that this threshold value may depend on several parameters, including the affinity between the filler and the matrix.

The extrudate temperatures are also indicated on Fig. 13. Several authors have reported that degradation of clay surfactant or the matrix can occur if the temperatures reached inside the extruder are too high (Cui et al., 2008; Domenech et al., 2012; Barbas et al., 2013; Gelfer et al., 2005). We observe in Fig. 13 that the optimal level of nanometric dispersion is achieved between $200^{\circ} \mathrm{C}$ and $217^{\circ} \mathrm{C}$. When the temperature reaches and exceeds $220^{\circ} \mathrm{C}$, the yield stress stabilizes around $400 \mathrm{~Pa}$ and no longer increases. Above $400 \mathrm{kWh} / \mathrm{t}$, higher energy levels, up to $1100 \mathrm{kWh} / \mathrm{t}$, appear to result in a similar exfoliation. It seems thus that, beside SME, the temperature reached by the nanocomposite is a key element for the clay exfoliation. It is important to provide enough energy to enable nanoscale dispersion, but by simultaneously trying to keep the lowest possible temperature. However, it is difficult to decouple the effects of temperature and SME, as these two parameters are directly connected. Another potential 
hypothesis explaining the level-off of the yield stress is that a too high energy could induce a breakage of the clay sheets. We can see on the TEM observations (Fig. 4) that the size of the clay sheets seems to be lower for higher screw speeds, which could limit the interactions between exfoliated platelets, and thus result in a lower yield stress for an equivalent level of exfoliation.

\section{Conclusion}

This study has evaluated the impact of high speed extrusion on the dispersion state of an organoclay in a polypropylene matrix. It was first shown that all screw speeds, from 100 to $1100 \mathrm{rpm}$, lead to an exfoliated structure. The formation of a percolated network was confirmed by rheological measurements. However, it was demonstrated that high screw speeds, above $600 \mathrm{rpm}$, appear to damage the polymer matrix. The approach we proposed allowed us to analyze the complex viscosity curves by correcting the degradation of the matrix. We were then able to confirm that high screw speeds (above $600 \mathrm{rpm}$ ) do not result in a better exfoliation.

One of the reasons for this limitation can be the thermal degradation of the chemical modifier of the clay, which results in a collapse of the clay galleries, and in turn prevents an optimal exfoliation state. Another reason can be the mechanical breakage of the clay sheets, resulting in a lower melt yield stress for an equivalent exfoliation level. Finally, the degradation of the matrix can also lower the level of shear stress inside the extruder during melt processing, which in turn reduces the level of exfoliation.

\section{Acknowledgements}

This study was carried out through the European project EVOLUTION, in the frame of the $7^{\text {th }}$ Framework Program (FP7/2007-2013), under grant agreement 314744. We are grateful to the EU for financial support. The authors greatly acknowledge the CCMA (Centre Commun de 
Microscopie Appliquée, University of Nice Sophia-Antipolis, Microscopy and Imaging platform Côte d'Azur, MICA) and its personal, more particularly Sophie Pagnotta for the sample preparations and TEM observations. 


\section{References}

Bahloul, W., Oddes, O., Bounor-Legaré, V., Mélis, F., Cassagnau P. and B. Vergnes, "Reactive extrusion processing of polypropylene/ $/ \mathrm{TiO}_{2}$ nanocomposites by in situ synthesis of the nanofillers: Experiments and modeling” A.I.Ch.E. J., 57, 2174-2184 (2011).

Barbas, J.M., Machado, A.V. and Covas, J.A., "Evolution of dispersion along the extruder during the manufacture of polymer-organoclay nanocomposites”, Chem. Eng. Sci., 98, 7787 (2013).

Barbas, J.M., Machado, A.V. and Covas, J.A., "Processing conditions effect on dispersion evolution in a twin-screw extruder: polypropylene-clay nanocomposites", Chem. Eng.Tech., 37, 257-266 (2014).

Canevarolo, S.V., “Chain scission distribution function for polypropylene degradation during multiple extrusions”, Polym. Deg. Stab., 709, 71-76 (2000).

Cassagnau, P., “Melt rheology of organoclay and fumed silica nanocomposites”, Polymer, 49, 2183-2196 (2008).

Cervantes-Uc, J.M., Cauich-Rodriguez, J.V., Vazquez-Torres, H., Garfias-Mesias, L.F. and Paul, D.R., "Thermal degradation of commercially available organoclays studied by TGAFTIR”, Thermochim. Acta, 457, 92-102 (2007).

Cho, J.W. and Paul, D.R., "Nylon 6 nanocomposites by melt compounding”, Polymer, 42, 1089-1094 (2001).

Cui, L., Khramov, D.M., Bielawski, C.W., Hunter, D.L., Yoon, P.J. and Paul, D.R., "Effect of organoclay purity and degradation on nanocomposite performance, Part 1: surfactant degradation”, Polymer, 49, 3751-3761 (2008). 
Dintcheva, N. T. and La Mantia, F. P., “Thermo-mechanical degradation of LDPE-based nanocomposites”, Macromol. Mat. Eng., 292, 855-862 (2007).

Doh, J.G. and Cho, I., "Synthesis and properties of polystyrene-organoammonium montmorillonite hybrid”, Polym. Bul., 41, 511-518 (1998).

Domenech, T., Peuvrel-Disdier, E. and Vergnes, B., "Influence of twin-screw processing conditions on structure and properties of polypropylene-organoclay nanocomposites”, Intern. Polym. Proc., 27, 517-526 (2012).

Domenech, T., Peuvrel-Disdier, E. and Vergnes, B., "The importance of specific mechanical energy during twin screw extrusion of organoclay based polypropylene nanocomposites”, Comp. Sci. Technol., 75, 7-14 (2013).

Domenech, T., Zouari, R., Peuvrel-Disdier, E. and Vergnes, B., "Formation of fractal-like structure in organoclay-based polypropylene nanocomposites”, Macromol., 47, 3417-3427 (2014)

Fasulo, P.D., Rodgers, W.R., Ottaviani, R.A. and Hunter, D.L., "Extrusion processing of TPO nanocomposites”, Polym. Eng. Sci., 44, 1036-1045 (2004).

Fel, E., Massardier, V., Mélis, F., Vergnes, B. and Cassagnau, P., "Residence time distribution in a high shear twin screw extruder”, Intern. Polym. Proc., 29, 71-80 (2014).

Fornes, T.D., Yoon, P.J. and Paul, D.R., "Polymer matrix degradation and color formation in melt processed nylon 6/clay nanocomposites”, Polymer, 44, 7545-7556 (2003).

Gelfer, M.Y., Burger, C., Chu, B., Hsiao, B.S., Drozdov, A.D., Si, M., Rafailovich, M., Sauer, B.B. and Gilman, J.W., "Relationships between structure and rheology in model nanocomposites of ethylene-vinyl-based copolymers and organoclays”, Macromol., 38, 3765-3775 (2005). 
Gilman, J.W., Jackson, C.L., Morgan, A.B., Harris, R., Giannelis, E.P., Wuthenow, M., Hilton, D. and Phillips, S.H., "Flammability properties of polymer-layered-silicate nanocomposites. Polypropylene and polystyrene nanocomposites”, Chem. Mat., 12, 1866$1873(2000)$.

Gloaguen, J.M. and Lefebvre, J.M., "Plastic deformation behaviour of thermoplastic/clay nanocomposites”, Polymer, 42, 5841-5847 (2001).

Gonzales-Gonzales, V.A., Neira-Velasquez, G. and Angulo-Sanchez, J.L., "Polypropylene chain scissions and molecular weight changes in multiple extrusion”, Polym. Deg. Stab., 60, 33-42 (1998).

Hegde, R.R., Bhat, G.S., Spruiell, J.E. and Benson, R., "Structure and properties of polypropylene-nanoclay composites.” J. Polym. Res., 20, 1-13 (2013).

Hinsken, H., Moss, S., Pauquet, J.R. and Zweifel, H., "Degradation of polyolefins during melt processing”, Polym. Deg. Stab., 34, 279-293 (1991).

Hong, C.H., Lee, Y.B., Bae, J.W., Jho, J.Y., Nam, B.U. and Hwang, T.W., "Preparation and mechanical properties of polypropylene/clay nanocomposites for automotive parts application”, J. Appl. Polym. Sci., 98, 427-433 (2005).

Incarnato, L., Scarfato, P., Russo, G.M., Di Maio, L., Iannelli, P. and Acierno, D., "Preparation and characterization of new melt compounded copolyamide nanocomposite", Polymer, 44, 4625-4634 (2003).

Kawasumi, M., Hasegawa, N., Kato, M. and Usuki, A., "Preparation and mechanical properties of polypropylene-clay hybrids”, Macromol., 30, 6333-6338 (1997).

Leonardi, F.: Détermination de la distribution des masses molaires d'homopolymères linéaires par spectrométrie mécanique, PhD Dissertation, Université de Pau et des Pays de l’Adour (1999). 
Lertwimolnun, W. and Vergnes, B., "Influence of compatibilizer and processing conditions on the dispersion of nanoclay in a polypropylene matrix.” Polymer, 46, 3462-3471 (2005).

Lertwimolnun, W. and Vergnes, B., "Effect of processing conditions on the formation of polypropylene/organoclay nanocomposites in a twin screw extruder”, Polym. Eng. Sci., 46, 314-323 (2006).

Lertwimolnun, W. and Vergnes, B., "Influence of screw profile and extrusion conditions on the microstructure of polypropylene/organoclay nanocomposites”, Polym. Eng. Sci., 47, 2100-2109 (2007).

Lin, B., Thu, A., Heim, H.-P., Scheel, G. and Sundararaj, U., "Nylon 66/clay nanocomposite structure development in a twin screw extruder”, Polym. Eng. Sci., 66, 824-834 (2009).

Louizi, M., Massardier, V. and Cassagnau, P., “Contribution of high-shear processing to the compatibilization of (PP/EPR)/PE ternary blends”, Intern. Polym. Proc., 29, 674-688 (2014).

Massam, J. and Pinnavaia, T.J., "Clay nanolayer reinforcement of a glassy epoxy polymer”, Mat. Res. Soc., 520, 223-232 (1998).

Médéric, P., Aubry, T. and Razafinimaro, T., "Structural and rheological properties as a function of mixing energy for polymer/layered silicate nanocomposites.” Intern. Polym. Proc., 24, 261-266 (2009).

Messersmith, P.B. and Giannelis, E.P., "Synthesis and barrier properties of poly( $(\varepsilon-$ caprolactone)-layered silicate nanocomposites.” J. Polym. Sci., 33, 1047-1057 (1995).

Modesti, M., Lorenzetti, A., Bon, D. and Besco, S., "Effect of processing conditions on morphology and mechanical properties of compatibilized polypropylene nanocomposites”, Polymer, 46, 10237-10245 (2005). 
Modesti, M., Lorenzetti, A., Bon, D. and Besco, S., "Thermal behaviour of compatibilised polypropylene nanocomposite: effect of processing conditions”, Polym. Deg. Stab., 91, $672-680$ (2006).

Nassar, N., Utracki, L.A. and Kamal, M.R. "Melt intercalation in montmorillonite/polystyrene nanocomposites”, Intern. Polym. Proc., 20, 423-431 (2005).

Peltola, P., Va, E., Vuorinen, J., Syrja, S. and Hanhi, K., “Effect of rotational speed of twin screw extruder on the microstructure and rheological and mechanical properties of nanoclay-reinforced polypropylene”, Polym. Eng. Sci., 46, 995-1000 (2006).

Scatteia, L., Scarfato, P. and Acierno, D., "Processing, rheology and structure of melt compounded PBT-clay nanocomposites having different chemical composition”, e-Polym., 23, 1-15 (2006).

Shah, R.K., and Paul, D.R., "Organoclay degradation in melt processed polyethylene nanocomposites”, Polymer, 47, 4075-4084 (2006).

Usuki, A., Kojima, Y., Kawasumi, M., Okada, A., Fukushima, Y., Kurauchi, T. and Kamigaito, O., “Synthesis of nylon 6-clay hybrid.” J. Mate. Res., 8, 1179-1184 (1992).

Vergnes, B., "The use of apparent yield stress to characterize exfoliation in polymer nanocomposites”, Intern. Polym. Proc., 26, 229-232 (2011).

Wang, Z., and Pinnavaia, T.J., "Nanolayer reinforcement of elastomeric polyurethane”, Chem. Mat., 10, 3769-3771 (1998).

Yano, K., Usuki, A. and Okada, A., "Synthesis and properties of polyimide-clay hybrid films.” J. Polym. Sci., 35, 2289-2294 (1997). 


\section{Figure captions}

Figure 1: Screw profile.

Figure 2: SEM images of the nanocomposites prepared at different screw speeds: a) 100 rpm, b) $300 \mathrm{rpm}$, c) $600 \mathrm{rpm}$, d) $900 \mathrm{rpm}$ and e) $1100 \mathrm{rpm}$.

Figure 3: Evolution of the area ratio with the screw speed $\left(T_{\text {barrel }}=180^{\circ} \mathrm{C}, Q=2.6 \mathrm{~kg} / \mathrm{h}\right)$.

Figure 4: TEM images of the nanocomposites prepared at different screw speeds: a) 100 rpm, b) $300 \mathrm{rpm}$, c) $600 \mathrm{rpm}$, d) $900 \mathrm{rpm}$ and e) $1100 \mathrm{rpm}$.

Figure 5: X-ray diffractograms of the nanocomposites prepared at different screw speeds.

Figure 6: Interlamellar distance of the nanocomposites prepared at different screw speeds. Extrudate temperatures are also indicated for each screw speed.

Figure 7: Complex viscosity $\eta^{*}$ of the nanocomposites PP/PP-g-MA/C20 and the matrix as function of angular frequency $\left(T=180^{\circ} \mathrm{C}\right.$, strain $\left.\gamma=1 \%\right)$.

Figure 8: Evolution of the complex viscosity of the matrix with the screw speed $\left(T=180^{\circ} \mathrm{C}\right.$, strain $\gamma=1 \%)$.

Figure 9: Reduced complex viscosity as function of reduced frequency for the samples extruded at different screw speeds $\left(T=180^{\circ} \mathrm{C}\right.$, strain $\left.\gamma=1 \%\right)$.

Figure10: Shift factor as function of screw speed.

Figure 11: Shifted nanocomposites complex viscosity curves.

Figure 12: Evolution of the melt yield stress with the screw speed $\left(T_{\text {barrel }}=180^{\circ} \mathrm{C}, Q=2.6\right.$ $\mathrm{kg} / \mathrm{h})$.

Figure 13: Evolution of a) the area ratio and b) the melt yield stress with the SME provided to the nanocomposites $\left(T_{\text {barrel }}=180^{\circ} \mathrm{C}, Q=2.6 \mathrm{~kg} / \mathrm{h}\right)$. Extrudate temperatures are also indicated for each screw speed. 


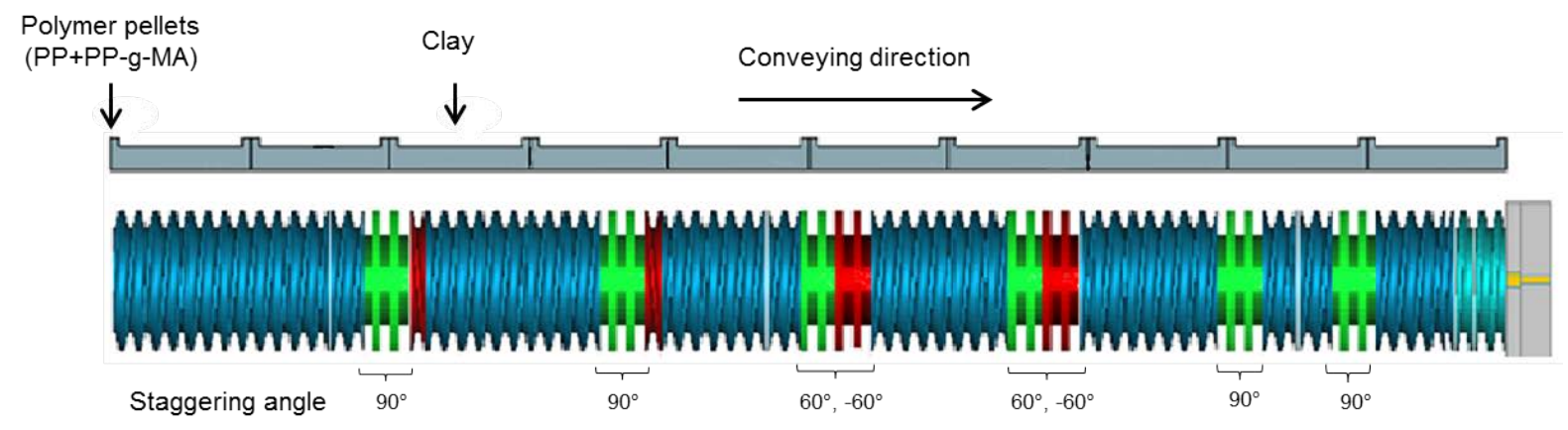

Figure 1: Screw profile 


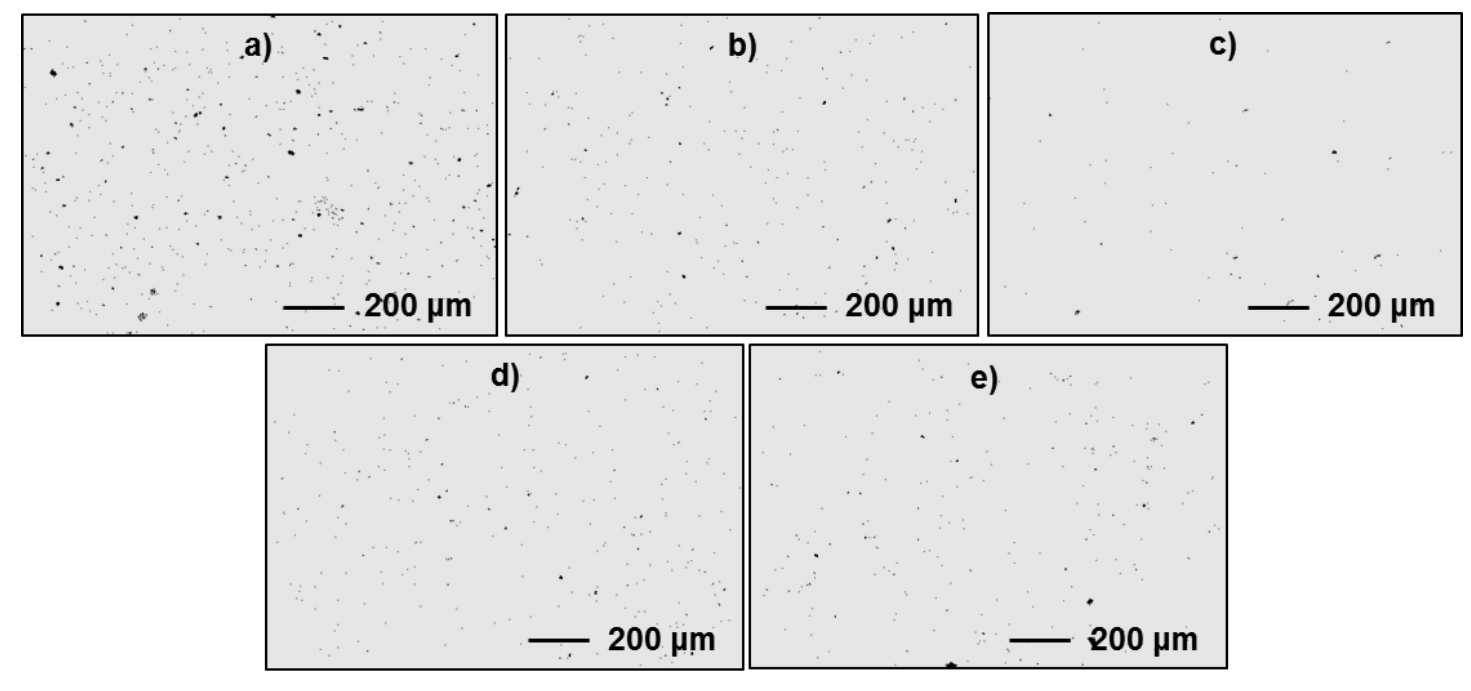

Figure 2: SEM images of the nanocomposites prepared at different screw speeds: a) 100 rpm, b) $300 \mathrm{rpm}$, c) $600 \mathrm{rpm}$, d) $900 \mathrm{rpm}$ and e) $1100 \mathrm{rpm}$ 


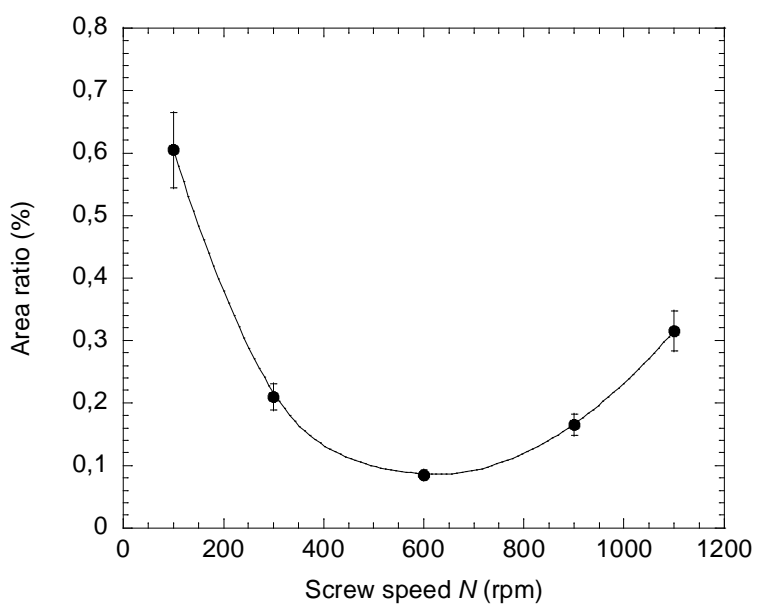

Figure 3: Evolution of the area ratio with the screw speed $\left(T_{\text {barrel }}=180^{\circ} \mathrm{C}, Q=2.6 \mathrm{~kg} / \mathrm{h}\right)$ 

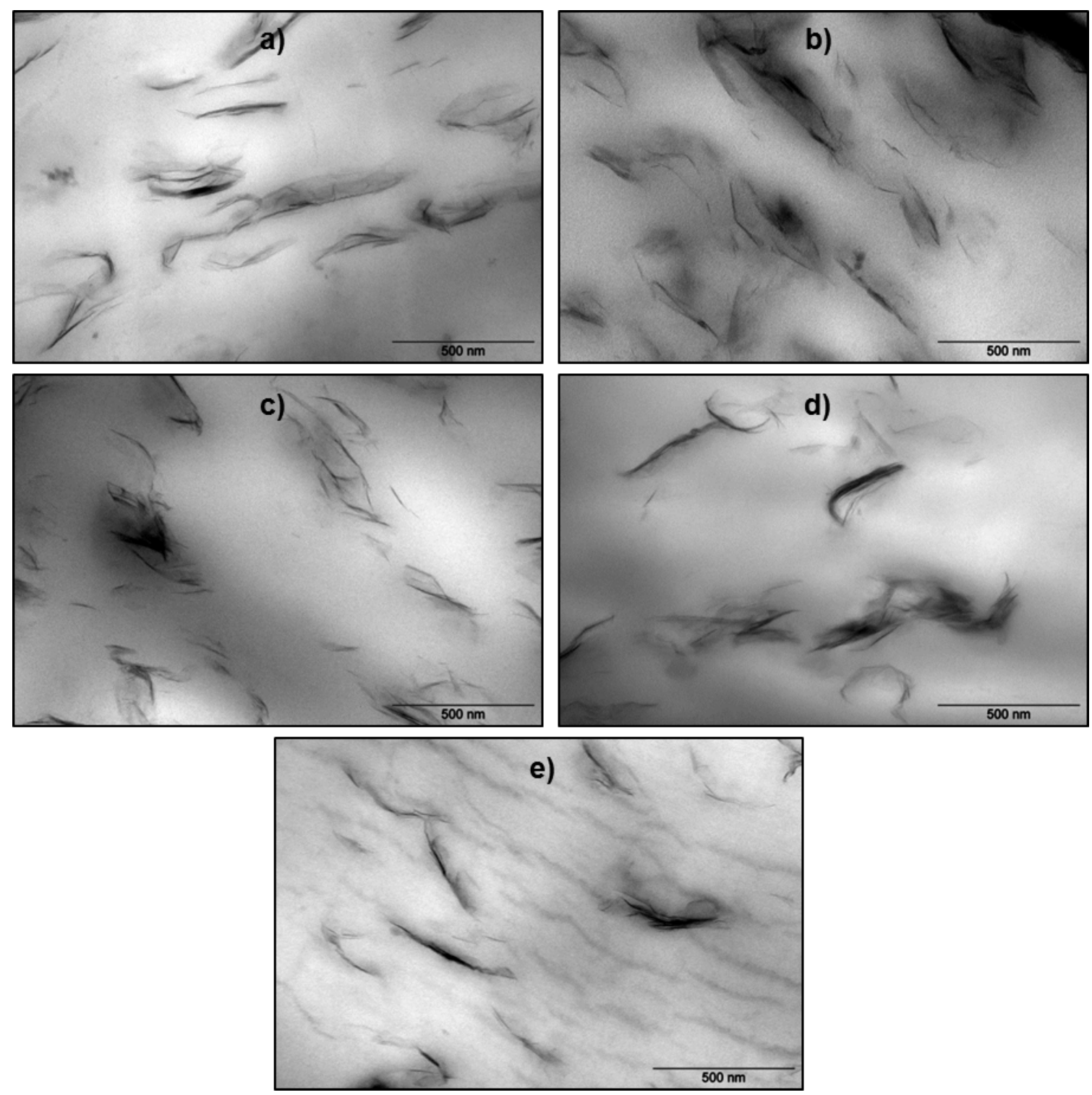

Figure 4: TEM images of the nanocomposites prepared at different screw speeds: a) $100 \mathrm{rpm}$, b) $300 \mathrm{rpm}$, c) $600 \mathrm{rpm}$, d) $900 \mathrm{rpm}$ and e) $1100 \mathrm{rpm}$ 


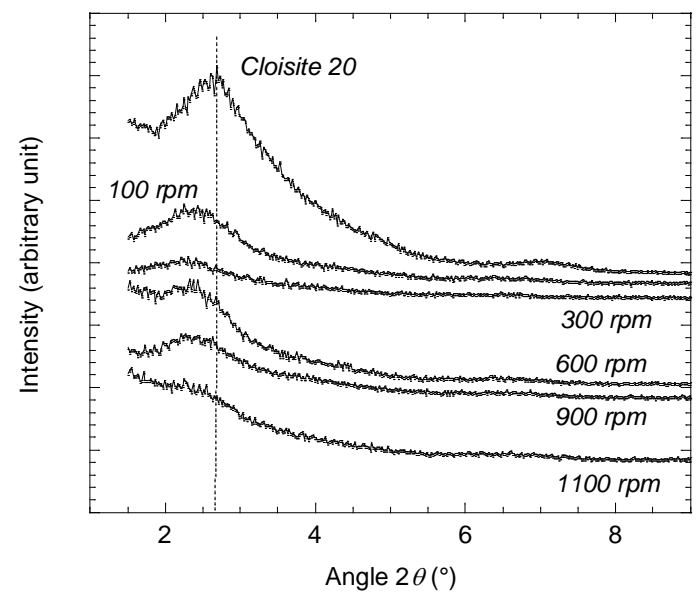

Figure 5: X-ray diffractograms of the nanocomposites prepared at different screw speeds 


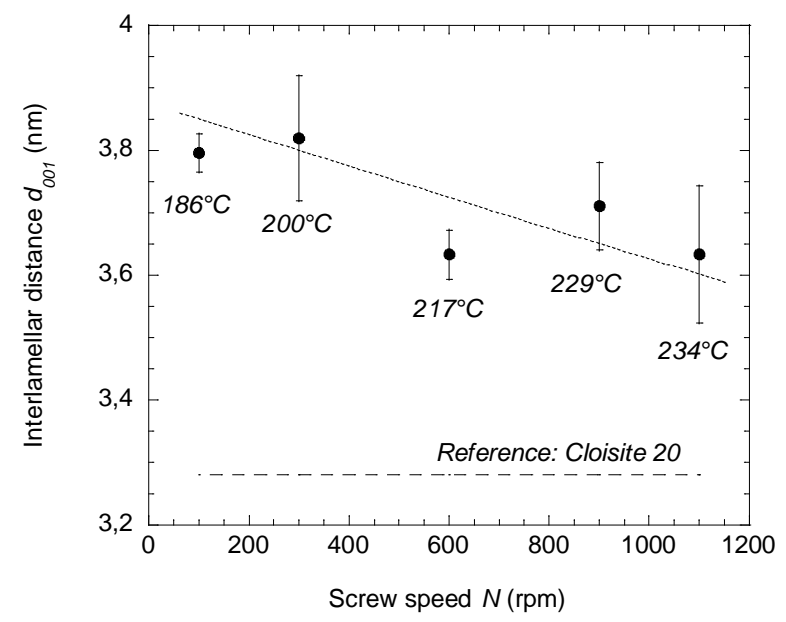

Figure 6: Interlamellar distance of the nanocomposites prepared at different screw speeds. Extrudate temperatures are also indicated for each screw speed. 


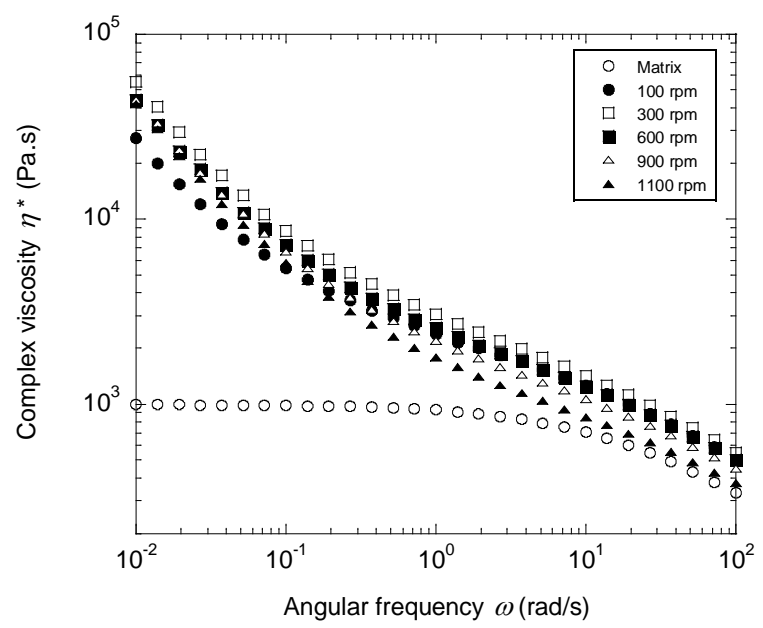

Figure 7: Complex viscosity $\eta^{*}$ of the nanocomposites PP/PP-g-MA/C20 and the matrix as function of angular frequency $\left(T=180^{\circ} \mathrm{C}\right.$, strain $\left.\gamma=1 \%\right)$ 


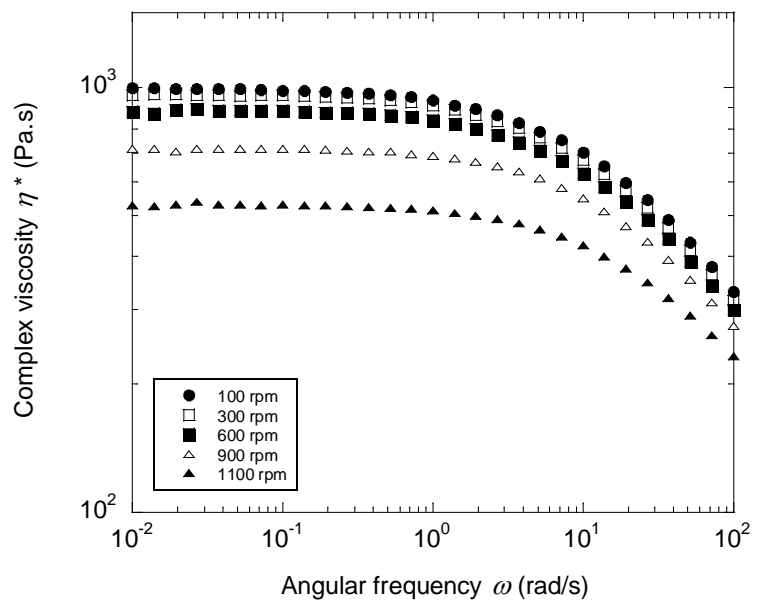

Figure 8: Evolution of the complex viscosity of the matrix with the screw speed $\left(T=180^{\circ} \mathrm{C}\right.$, strain $\gamma=1 \%)$ 


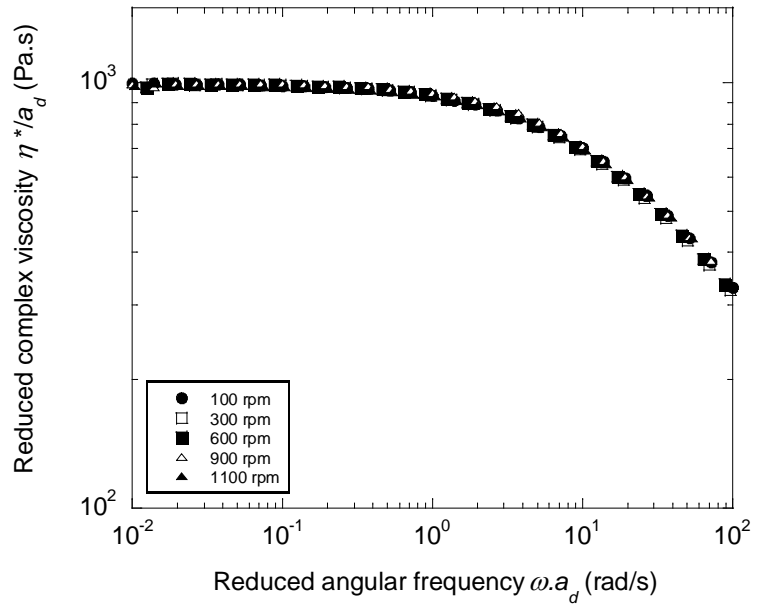

Figure 9: Reduced complex viscosity as function of reduced frequency for the samples extruded at different screw speeds $\left(T=180^{\circ} \mathrm{C}\right.$, strain $\left.\gamma=1 \%\right)$. 


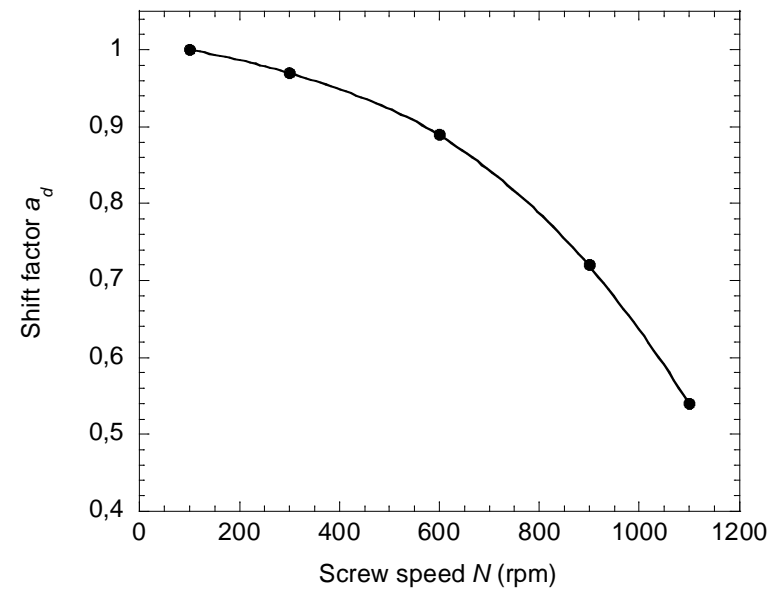

Figure10: Shift factor as function of screw speed. 


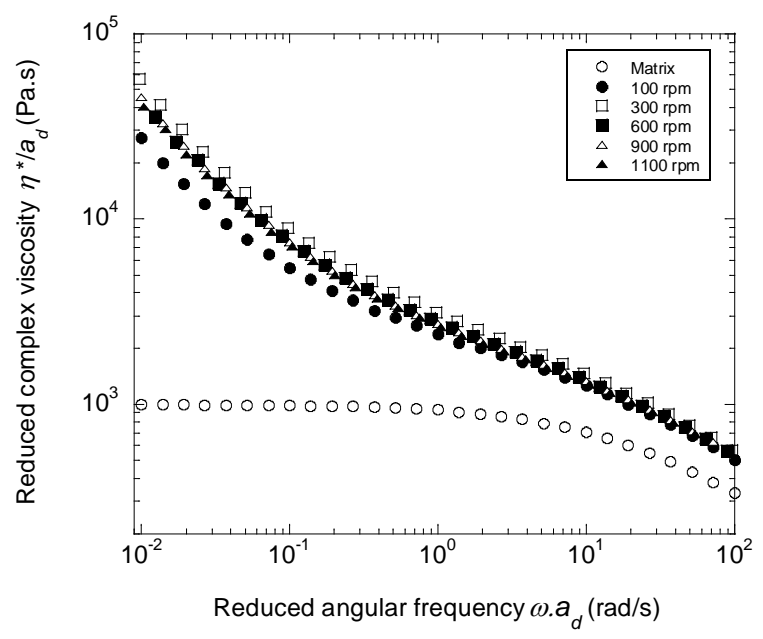

Figure 11: Nanocomposites complex viscosity curves corrected for matrix degradation $(T=$ $180^{\circ} \mathrm{C}$, strain $\left.\gamma=1 \%\right)$. 


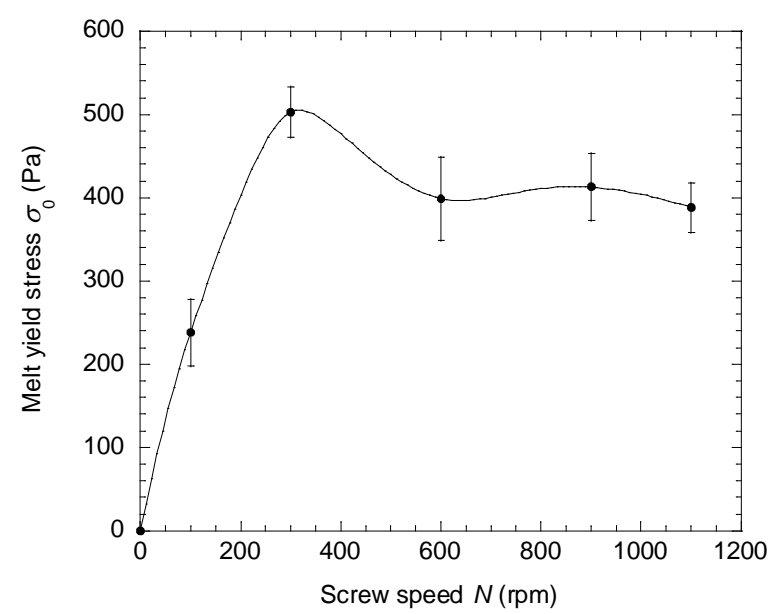

Figure 12: Evolution of the melt yield stress with the screw speed $\left(T_{\text {barrel }}=180^{\circ} \mathrm{C}, Q=2.6\right.$ $\mathrm{kg} / \mathrm{h}$ ). 

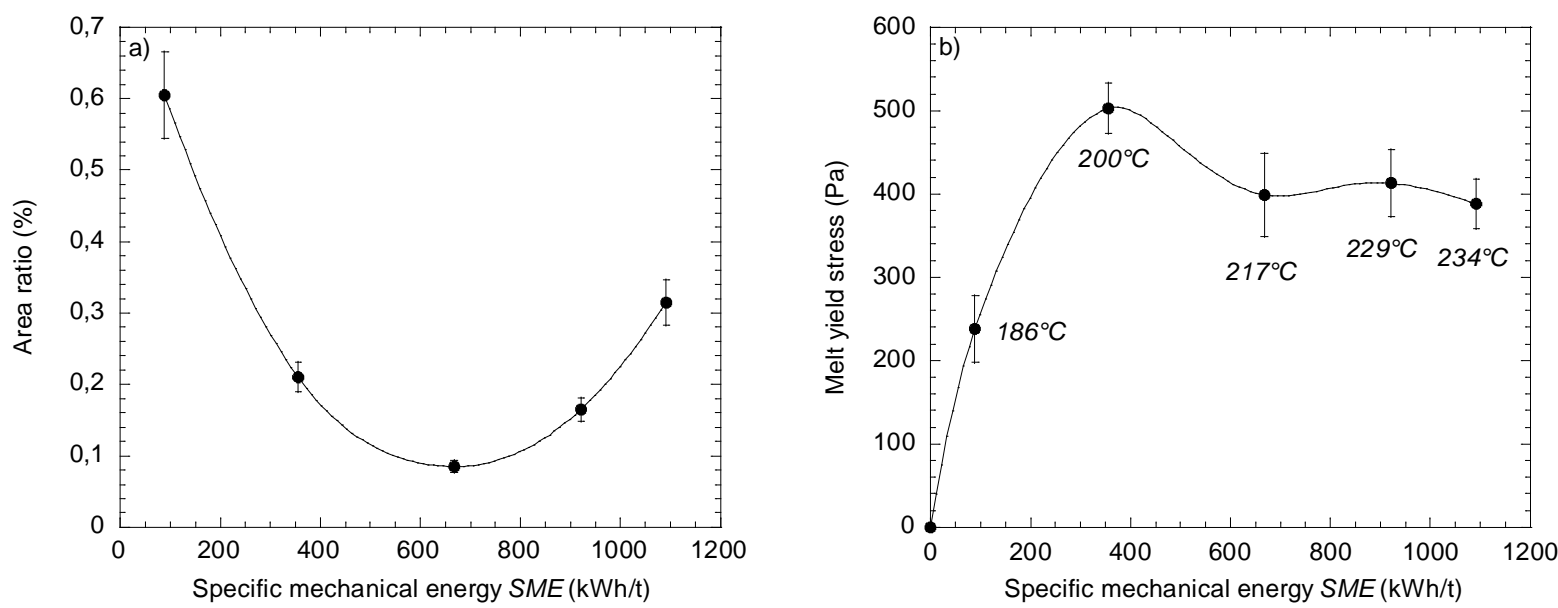

Fig. 13: Evolution of a) the area ratio and b) the melt yield stress with the SME provided to the nanocomposites $\left(T_{\text {barrel }}=180^{\circ} \mathrm{C}, Q=2.6 \mathrm{~kg} / \mathrm{h}\right)$. Extrudate temperatures are also indicated for each screw speed. 